Научная статья

УДК 332.1

DOI https://doi.org/10.24866/VVSU/2073-3984/2021-4/189-198

\title{
Т.П. Филичева
}

Владивостокский государственный университет экономики и сервиса.

Владивосток. Россия

\section{Регулирование деятельности стивидоров по выполнению ими требований природоохранного законодательства}

\begin{abstract}
Аннотация. В соответствии с договором аренды недвижимого имущества в морском порту, используемого для перевалки опасных грузов, арендодатель не должен препятствовать или вмешиваться в хозяйственную деятельность арендатора, связанную с использованием арендуемых им объектов, если она не противоречит условиям договора. Отсутствие четко поставленных экологических требований применительно к каждому морскому порту и технологии перевалки опасных грузов, которые стали бы обязательными для арендатора в рамках договора аренды, не позволяют арендодателю контролировать их исполнение. В этих условиях арендодатель может определить критерии выполнения экологических требований, обязательные для арендатора при заключении договора аренды. Регулирование деятельности стивидора в морском порту базируется на критериях значимости экологических аспектов, основанных на показателях негативного воздействия на окружающую среду.
\end{abstract}

Ключевые слова: стивидоры, арендатор, арендодатель, перевалка опасных грузов в морском порту, экологические аспекты, критерии, воздействие на окружающую среду, идентификация, критерии значимости, ответственность.

T.P. Philicheva

Vladivostok State University of Economics and Service Vladivostok. Russia

\section{Regulation of stevedores' activities to meet the requirements of environmental legislation}

Филичева Татьяна Петровна - канд. геогр. наук, доцент, доцент Института экономики и управления; e-mail: Tatyana.Filicheva@vvsu.ru 


\begin{abstract}
In accordance with the lease agreement for immovable property in the seaport used for transshipment of dangerous goods, the lessor must not interfere or interfere with the economic activities of the lessee related to the use of the leased facilities, if it does not contradict the terms of the contract. The absence of clearly defined environmental requirements for each seaport and the technology of transshipment of dangerous goods, which would become mandatory for the lessee under the lease agreement, do not allow the lessor to control their implementation. In these conditions, the lessor can meet the criteria for meeting environmental requirements that are mandatory for the lessee when concluding a lease agreement. The regulation of the stevedore's activity in the seaport is based on the criteria of the importance of environmental aspects based on indicators of negative impact on the environment.
\end{abstract}

Keywords: stevedores, lessee, lessor, transshipment of dangerous goods at the seaport, environmental aspects, criteria, environmental impact, identification, significance criteria, responsibility.

\title{
Введение
}

В ранее опубликованной автором статье «Правовые аспекты экологических проблем открытой перевалки угля в морских портах» [1] обсуждались правовые аспекты исполнения стивидорами требований договора аренды объектов инфраструктуры морского порта, используемых ими для перевалки опасных грузов (каменного угля, минеральных удобрений, химических грузов) [2]. Договор аренды заключается между стивидорами (арендаторами) и федеральным государственным унитарным предприятием, в чьем хозяйственном ведении находятся данные объекты (арендодателем) [3].

Анализ сложившейся системы отношений арендодателя и арендаторов в сфере исполнения требований экологического законодательства, пробелов в правовом регулировании этих отношений выявил необходимость стимулирования арендаторов соблюдать требования законодательства и выполнять мероприятия, направленные на снижение или ликвидацию неблагоприятного воздействия на окружающую среду и здоровье населения, своевременно исполнять предписания органов экологического надзора.

Несмотря на наличие в договоре аренды обязательств арендатора по соблюдению арендатором требований экологического законодательства, их размытость и неконкретность применительно к каждому морскому порту и технологии перевалки делают эти обязательства необязательными для стивидоров и неконтролируемыми со стороны арендодателя, который не имеет юридической возможности самостоятельно конкретизировать экологические требования и контролировать их исполнение.

\section{Основная часть}

Регулирование отношений арендодателя с арендаторами (стивидорами) в части исполнения ими экологических требований и организации контроля с целью предотвращения загрязнения окружающей среды и возникновения экологических рисков, связанных с перевалкой опасных грузов в морском порту, требует создания специальных форм взаимодействия, которые устанавливали бы типовые условия, обязательные для исполнения всеми арендаторами при заключении договора аренды. К таким условиям относится иден- 
тификация экологических аспектов деятельности по перевалке опасных грузов в морском порту.

В процессе идентификации экологических аспектов рассматриваются все виды воздействия на окружающую среду, возникающего при перевалке опасных грузов, и наличие у стивидоров обязательной природоохранной документации как одного из обязательных требований экологического законодательства. К видам воздействия относятся выбросы и сбросы загрязняющих веществ, образование отходов производства и потребления, шумовое воздействие и воздействие на биоразнообразие.

Идентификация экологических аспектов учитывает такие процессы деятельности арендатора, как:

- изменение технологических процессов перевалки грузов;

- реконструкция и модернизация технологического оборудования;

- аварийные ситуации на различных этапах технологического процесса;

- изменение совокупного объема перевалки грузов (в тоннах);

- изменение условий договора аренды по инициативе арендатора;

- изменение экологических требований законодательства, касающихся перевалки опасных грузов.

Идентификация экологических аспектов учитывает:

- эксплуатационный (штатный) режим работы технологического оборудования;

- аварийный режим работы технологического оборудования на всех или отдельных этапах технологического процесса;

- природоохранные мероприятия;

- использование земельных участков в границах санитарно-защитной зоны;

- конфликты с общественностью и иными заинтересованными сторонами по природоохранным вопросам и др.

При оценке воздействия на окружающую среду, которая проводится арендодателем по отчетам производственного экологического контроля арендатора, рассматриваются следующие сведения:

- о выбросах (угольной пыли, метана, оксидов азота, диоксида серы, сажи и иных) в соответствии с утвержденными нормативами предельно допустимых выбросов и их превышении;

- о сбросах загрязняющих веществ со сточными водами, если сброс осуществляется в соответствии с Разрешением на сброс и Решением о предоставлении водного объекта в пользование, и их превышении;

- об образовываемых и размещаемых отходах в соответствии с утвержденным проектом нормативов образования отходов и лимитов на их размещение (ПНООЛР);

- о шумовом и ином физическом воздействии;

- об авариях и инцидентах, повлекших за собой загрязнение окружающей среды и др. (табл. 1). 
Перечень обязательной разрешительной документации в соответствии с требованиями природоохранного законодательства (по состоянию на 31.01.2021 г.)

\begin{tabular}{|c|c|c|}
\hline $\begin{array}{l}\text { № } \\
\Pi / \Pi\end{array}$ & Название документа & Комментарий \\
\hline 1 & $\begin{array}{l}\text { Свидетельство о постановке на } \\
\text { учет объекта НВОС }\end{array}$ & \\
\hline 2 & $\begin{array}{l}\text { Декларация о воздействии на } \\
\text { окружающую среду }\end{array}$ & $\begin{array}{l}\text { Если объект II категории относится к одной из } \\
\text { областей применения новых доступных техноло- } \\
\text { гий (НДТ), в отношении которой уже утвержден } \\
\text { отраслевой информационно-технический справоч- } \\
\text { ник по НДТ, то эксплуатирующее такой объект } \\
\text { лицо вправе обратиться за получением Комплекс- } \\
\text { ного экологического разрешения }\end{array}$ \\
\hline \multirow[t]{2}{*}{3} & $\begin{array}{l}\text { Документы по охране атмосфер- } \\
\text { ного воздуха: } \\
\text { материалы инвентаризации вы- } \\
\text { бросов загрязняющих веществ в } \\
\text { атмосферный воздух и проект } \\
\text { нормативов предельно допусти- } \\
\text { мых выбросов; }\end{array}$ & $\begin{array}{l}\text { Инвентаризация источников выбросов загрязняю- } \\
\text { щих веществ заключается в документированном } \\
\text { описании (в том числе на основе дополнительных } \\
\text { измерений) общего количества, расположения ста- } \\
\text { ционарных источников, включая их соответствие } \\
\text { установленным нормативам. Обязательной являет- } \\
\text { ся периодическая (один раз в пять лет) инвентари- } \\
\text { зация источников выбросов загрязняющих ве- } \\
\text { ществ. Разрабатываются в соответствии с Феде- } \\
\text { ральным законом «Об охране атмосферного возду- } \\
\text { ха» }\end{array}$ \\
\hline & $\begin{array}{l}\text { санитарно-эпидемиологическое } \\
\text { заключение о соответствии нор- } \\
\text { мативов предельно допустимых } \\
\text { выбросов санитарным правилам; } \\
\text { программа (план-график) контро- } \\
\text { ля качества атмосферного воздуха } \\
\text { на границе санитарно-защитной } \\
\text { зоны и на контрольных точках, } \\
\text { согласованная с органами сани- } \\
\text { тарно-эпидемиологического над- } \\
\text { зора; } \\
\text { результаты производственного } \\
\text { контроля за соблюдением уста- } \\
\text { новленных нормативов выбросов }\end{array}$ & \\
\hline 4 & $\begin{array}{l}\text { Документы по охране водных } \\
\text { объектов: } \\
\text { решение о предоставлении вод- } \\
\text { ного объекта в пользование для } \\
\text { сброса сточных вод; }\end{array}$ & В случае наличия очистных сооружений \\
\hline
\end{tabular}


Т.П. Филичева. Регулирование деятельности стивидоров по выполнению ими требований ...

Окончание табл. 1

\begin{tabular}{|c|c|c|}
\hline № & Название документа & Комментарий \\
\hline & $\begin{array}{l}\text { нормативы допустимых сбросов } \\
\text { (НДС) веществ и микроорганиз- } \\
\text { мов } \\
\text { в водные объекты, согласован- } \\
\text { ные и утверждённые в установ- } \\
\text { ленном порядке }\end{array}$ & $\begin{array}{l}\text { Для объектов НВОС II категории нормативы воз- } \\
\text { действия устанавливаются для веществ I, II класса } \\
\text { опасности (веществ, обладающих канцерогенными, } \\
\text { мутагенными свойствами) }\end{array}$ \\
\hline 5 & $\begin{array}{l}\text { Документация по обращению } \\
\text { с отходами: } \\
\text { проект нормативов образования } \\
\text { отходов и лимитов на их разме- } \\
\text { щение; } \\
\text { паспорт на каждый вид отхода; } \\
\text { журналы учета отходов }\end{array}$ & $\begin{array}{l}\text { Определяется Федеральным законом «Об отходах } \\
\text { производства и потребления» }\end{array}$ \\
\hline 6 & $\begin{array}{l}\text { Программа производственного } \\
\text { экологического контроля (ПЭК) }\end{array}$ & $\begin{array}{l}\text { Программа ПЭК содержит сведения: } \\
\text { об инвентаризации выбросов и сбросов загряз- } \\
\text { няющих веществ и их источников; } \\
\text { об инвентаризации отходов и объектов их разме- } \\
\text { щения и др. }\end{array}$ \\
\hline 7 & $\begin{array}{l}\text { Отчет о результатах производст- } \\
\text { венного экологического контро- } \\
\text { ля }\end{array}$ & \\
\hline 8 & Декларация о плате за НВОС & $\begin{array}{l}\text { Декларация по НВОС - документ, оформляемый } \\
\text { один раз по итогам года }\end{array}$ \\
\hline 9 & $\begin{array}{l}\text { Природоохранная статистиче- } \\
\text { ская отчетность: отчет 2-ТП } \\
\text { (воздух); отчет 2-ТП (отходы); } \\
\text { отчет 2-ТП (рекультивация) (при } \\
\text { наличии); форма } 4 \text { - ОС (теку- } \\
\text { щие затраты) }\end{array}$ & \\
\hline 10 & $\begin{array}{l}\text { Сертификаты обучения руководи- } \\
\text { телей и специалистов по курсу } \\
\text { «Обеспечение экологической безо- } \\
\text { пасности руководителями (спе- } \\
\text { циалистами) общехозяйственных } \\
\text { систем управления» }\end{array}$ & $\begin{array}{l}\text { Обучение может проводиться в любом сертифици- } \\
\text { рованном центре }\end{array}$ \\
\hline 11 & $\begin{array}{l}\text { Свидетельства о квалификации в } \\
\text { сфере обращения с отходами } \\
\text { производства и потребления }\end{array}$ & \\
\hline 12 & $\begin{array}{l}\text { Проект организации санитарно- } \\
\text { защитной зоны (С33) }\end{array}$ & $\begin{array}{l}\text { Проект С } 33 \text { разрабатывается для действующих, } \\
\text { планируемых к строительству и реконструируемых } \\
\text { объектов НВОС }\end{array}$ \\
\hline
\end{tabular}


При оценке воздействия учитываются масштаб и продолжительность воздействия, площадь распространения загрязнения (табл. 2).

Таблица 2

Показатели значимости воздействий на окружающую среду

\begin{tabular}{|l|l|l|l|}
\hline \multirow{2}{*}{$\begin{array}{c}\text { Показатели } \\
\text { значимости }\end{array}$} & \multicolumn{3}{|c|}{ Категория значимости } \\
\cline { 2 - 5 } & \multicolumn{1}{|c|}{ Незначительное } & \multicolumn{1}{|c|}{ Значимое } & \multicolumn{1}{|c|}{ Значительное } \\
\hline Масштаб & $\begin{array}{l}\text { В пределах отдель- } \\
\text { ных стадий техноло- } \\
\text { гического цикла или } \\
\text { технологического } \\
\text { оборудования }\end{array}$ & $\begin{array}{l}\text { В пределах отдель- } \\
\text { ных стадий техноло- } \\
\text { гического цикла или } \\
\text { технологического } \\
\text { оборудования }\end{array}$ & $\begin{array}{l}\text { Все стадии технологи- } \\
\text { ческого цикла }\end{array}$ \\
\hline Продолжительность & $\begin{array}{l}\text { Короткий период, не } \\
\text { более 1 месяца }\end{array}$ & $\begin{array}{l}\text { Не более трех меся- } \\
\text { цев }\end{array}$ & 3-6 месяцев и более \\
\hline $\begin{array}{l}\text { Площадь распро- } \\
\text { странения }\end{array}$ & $\begin{array}{l}\text { Воздействие в пре- } \\
\text { делах промплощадки }\end{array}$ & $\begin{array}{l}\text { Воздействие в преде- } \\
\text { лах санитарно- } \\
\text { защитной зоны }\end{array}$ & $\begin{array}{l}\text { Воздействие отмечает- } \\
\text { ся за границей сани- } \\
\text { тарно-защитной зоны. } \\
\text { Сложившийся уровень } \\
\text { загрязнения на терри- } \\
\text { тории представляет } \\
\text { угрозу для здоровья } \\
\text { населения, биоразно- } \\
\text { образия и др. }\end{array}$ \\
\hline
\end{tabular}

При оценке легитимности деятельности, которая осуществляется на объектах II категории, в соответствии с требованиями экологического законодательства арендодатель обязан иметь:

- обязательную разрешительную документацию, утвержденную в установленном законодательством порядке (Декларацию о воздействии на окружающую среду, Декларацию о плате за НВОС, Комплексное экологическое разрешение, проект нормативов образования отходов и лимитов на их размещение, свидетельство о постановке на учет объекта негативного воздействия);

- отчеты о выполнении планов (программ) природоохранных мероприятий или программы производственного экологического контроля, производственного экологического контроля;

- утверждённый проект санитарно-защитной зоны (или отчет об ее установлении на дату оценки);

- отчет об использовании земельных участков в границах санитарнозащитной зоны;

- сертификаты обучения в области охраны окружающей среды, экологической безопасности;

- сертификаты обучения лиц, допущенных к обращению с отходами I-IV класса опасности; лиц, ответственных за допуск работников к работе с отходами I-IV класса опасности. 
Т.П. Филичева. Регулирование деятельности стивидоров по выполнению ими требований ...

Требование о разработке санитарно-защитной зоны вокруг объектов и производств, являющихся источниками выбросов загрязняющих веществ, относится к основным требованиям санитарно-эпидемиологического законодательства. С33 - специальная территория с особым режимом использования (защита населения расстоянием), размер которой обеспечивает уменьшение воздействия загрязнения на атмосферный воздух до значений, установленных гигиеническими нормативами, а для предприятий I и II класса опасности - до величин приемлемого риска для здоровья населения [3]. Обязательно наличие у руководителя предприятия свидетельства о прохождении обучения по курсу «Обеспечение экологической безопасности руководителями (специалистами) общехозяйственных систем управления»; проверяется в обязательном порядке [5, 6].

При оценке легитимности учитываются сведения о конфликтах с населением и общественностью, административные штрафы и судебные по поводу неисполнения предписаний органов экологического надзора, судебные иски по нанесенному экологическому вреду (табл. 3 ).

Таблица 3

Показатели легитимности деятельности стивидора в соответствии с требованиями природоохранного законодательства

\begin{tabular}{|l|l|l|l|}
\hline \multicolumn{1}{|c|}{$\begin{array}{l}\text { Показатели } \\
\text { значимости }\end{array}$} & \multicolumn{3}{|c|}{ Категория значимости } \\
\cline { 2 - 4 } & Незначительное & \multicolumn{1}{|c|}{ Значимое } & \multicolumn{1}{|c|}{ Значительное } \\
\hline Продолжительность & Незначительная & Длительное время & Постоянное \\
\hline $\begin{array}{l}\text { Конфликты с населе- } \\
\text { нием и общественно- } \\
\text { стью }\end{array}$ & Отсутствуют & $\begin{array}{l}\text { Единичные конфлик- } \\
\text { ты }\end{array}$ & Постоянные \\
\hline $\begin{array}{l}\text { Штрафы, судебные } \\
\text { иски по поводу неис- } \\
\text { полнения предписаний }\end{array}$ & Отсутствуют & $\begin{array}{l}\text { Отсутствуют, но } \\
\text { отмечены повторные } \\
\text { предписания об уст- } \\
\text { ранении нарушений }\end{array}$ & $\begin{array}{l}\text { Административные } \\
\text { шски судебные }\end{array}$ \\
\hline $\begin{array}{l}\text { Судебные иски по } \\
\text { нанесенному вреду ОС }\end{array}$ & Отсутствуют & Отсутствуют & $\begin{array}{l}\text { Судебные иски по } \\
\text { нанесенному вреду ОС }\end{array}$ \\
\hline
\end{tabular}

При выполнении проектных работ, испытаниях нового оборудования, реконструкции технологических линий и т.д. арендатор должен обеспечить соответствие применяемых технологий и организации работ действующим ГОСТам, СНиПам, ТУ и другим нормативным документам, а также гарантировать исправность техники и оборудования, используемых им на арендуемых объектах.

Арендатор также обязан иметь:

- положительное заключение государственной экологической экспертизы, санитарно-эпидемиологическое заключение на проекты технической документации и на поставляемую новую технику, технологии, использование которых может оказать воздействие на окружающую среду; 
- утвержденную в установленном порядке санитарно-защитную зону;

- сертификаты соответствия поставляемого оборудования, технических устройств и материалов требованиям российского природоохранного законодательства.

Немаловажным условием является соблюдение экологических требований подрядчиками и поставщиками оборудования, работающими в морском порту. Арендаторы должны обеспечить:

- проведение инструктажа по технике безопасности и экологической безопасности перед получением акта-допуска на выполнение работ для всех работников;

- проведение строительно-монтажных работ на основании проектной документации с учетом оценки воздействия на окружающую среду в случае, если эта процедура предусмотрена для данного вида деятельности.

В период проведения работ арендатор обязуется производить производственный контроль, включающий мониторинг выполняемых работ, контроль воздействия на окружающую среду в процессе работ (выбросы, сбросы) и контроль за образованием и размещением строительных и коммунальных отходов.

Выявленные аспекты могут классифицироваться по значимости (табл. 4).

Таблица 4

\section{Реестр экологических аспектов легитимности деятельности арендатора}

\begin{tabular}{|c|c|c|}
\hline $\begin{array}{l}\text { Значимость } \\
\text { аспекта }\end{array}$ & $\begin{array}{c}\text { Воздействие на окружающую } \\
\text { среду }\end{array}$ & Легитимность деятельности арендатора \\
\hline Незначительное & $\begin{array}{l}\text { Воздействие локальное, в преде- } \\
\text { лах промплощадки, длится не } \\
\text { более } 1 \text { месяца, за границей С33 } \\
\text { не отмечается }\end{array}$ & $\begin{array}{l}\text { Вся обязательная документация присут- } \\
\text { ствует, конфликты с населением отсут- } \\
\text { ствуют, штрафов и исков не было }\end{array}$ \\
\hline Значимое & $\begin{array}{l}\text { Воздействие длится не более трех } \\
\text { месяцев, отмечается загрязнение } \\
\text { разных компонентов окружающей } \\
\text { среды, угрозы для населения не } \\
\text { представляет }\end{array}$ & $\begin{array}{l}\text { Воздействие достаточно длительное, } \\
\text { но отмечены только единичные по- } \\
\text { вторные предписания органов надзо- } \\
\text { ра, единичные конфликты }\end{array}$ \\
\hline Значительное & $\begin{array}{l}\text { Воздействие длится от 3-6 и бо- } \\
\text { лее месяцев, происходит на любой } \\
\text { стадии технологического процес- } \\
\text { са, изменения окружающей среды } \\
\text { отмечаются за границей С33, а } \\
\text { сложившийся уровень загрязне- } \\
\text { ния представляет угрозу для насе- } \\
\text { ления и биоразнообразия }\end{array}$ & $\begin{array}{l}\text { Происходят «открытые» конфликты с } \\
\text { населением; отмечаются длительные, } \\
\text { систематические нарушения предпи- } \\
\text { саний природоохранных органов и } \\
\text { возможны иски за нанесение вреда } \\
\text { ОС; не устраняются допущенные на- } \\
\text { рушения после письменного предпи- } \\
\text { сания арендодателя; имеются судеб- } \\
\text { ные решения, которые на дату кон- } \\
\text { троля находятся на принудительном } \\
\text { исполнении }\end{array}$ \\
\hline
\end{tabular}


Выводы

Разработка и внедрение системы критериев экологических аспектов перевалки опасных грузов в морском порту позволит повысить уровень обеспечения экологической безопасности на объектах федерального имущества, расположенного в морском порту, с учетом риска возникновения чрезвычайных ситуаций техногенного характера, распределить ответственность между сторонами договора аренды, а также создать дополнительное основание для досрочного расторжения договора аренды с арендаторами, не соблюдающими требования экологического законодательства.

1. Филичева Т.П. Правовые аспекты экологических проблем открытой перевалки угля в морских портах // Территория новых возможностей. Вестник Владивостокского государственного университета экономики и сервиса. - 2021. - Т. 13, № 2. - С. 8998.

2. О морских портах в Российской Федерации и о внесении изменений в отдельные законодательные акты Российской Федерации: Федеральный закон от 08.11.2007 № 261-Ф3 (ред. от 08.12.2020), ст. 4.

3. Об утверждении Порядка сдачи в аренду федерального имущества, расположенного в морском порту, находящегося в хозяйственном ведении федеральных государственных унитарных предприятий, подведомственных Федеральному агентству морского и речного транспорта: приказ Минтранса РФ от 02.11.2009 г. № 191т.

4. СанПиН 2.2.1/2.1.1.1200-03 «Санитарно-защитные зоны и санитарная классификация предприятий, сооружений и иных объектов».

5. Об охране окружающей среды: Федеральный закон от 10.01.2002 № 7-Ф3.

6. Об отходах производства и потребления: Федеральный закон от 24.06.1998 № 89-Ф3.

7. Экономические и экологические проблемы развития российских угольных терминалов: аналитический доклад. - Москва: Институт проблем естественных монополий, 2018.

\section{Транслитерация}

1. Filicheva T.P. Pravovye aspekty ekologicheskih problem otkrytoj perevalki uglya v morskih portah // Territoriya novyh vozmozhnostej. Vestnik Vladivostokskogo gosudarstvennogo universiteta ekonomiki i servisa. - 2021. - T. 13, № 2. - S. 89-98.

2. O morskih portah v Rossijskoj Federacii i o vnesenii izmenenij v otdel'nye zakonodatel'nye akty Rossijskoj Federacii: Federal'nyj zakon ot 08.11.2007 № 261-FZ (red. ot 08.12.2020), st. 4.

3. Ob utverzhdenii Poryadka sdachi v arendu federal'nogo imushchestva, raspolozhennogo v morskom portu, nahodyashchegosya $\mathrm{v}$ hozyajstvennom vedenii federal'nyh gosudarstvennyh unitarnyh predpriyatij, podvedomstvennyh Federal'nomu agentstvu morskogo i rechnogo transporta: prikaz Mintransa RF ot 02.11.2009 g. № 191t.

4. SanPiN 2.2.1/2.1.1.1200-03 «Sanitarno-zashchitnye zony i sanitarnaya klassifikaciya predpriyatij, sooruzhenij i inyh ob"ektov».

5. Ob ohrane okruzhayushchej sredy: Federal'nyj zakon ot 10.01.2002 № 7-FZ.

6. Ob othodah proizvodstva i potrebleniya: Federal'nyj zakon ot 24.06.1998 № 89-FZ.

7. Ekonomicheskie i ekologicheskie problemy razvitiya rossijskih ugol'nyh termina-lov: analiticheskij doklad. - Moskva: Institut problem estestvennyh monopolij, 2018. 
(С Т.П. Филичева, 2021

Для цитирования: Филичева Т.П. Регулирование деятельности стивидоров по выполнению ими требований природоохранного законодательства // Территория новых возможностей. Вестник Владивостокского государственного университета экономики и сервиса. - 2021. - Т. 13, № 4. - С. 189-198.

For citation: Philicheva T. P. Regulation of stevedores' activities to meet the requirements of environmental legislation, The Territory of New Opportunities. The Herald of Vladivostok State University of Economics and Service, 2021, Vol. 13, № 4, pp. 189-198.

DOI https://doi.org/10.24866/VVSU/2073-3984/2021-4/189-198

$\begin{array}{lll}\text { Дата поступления: } & \text { Одобрена после рецензирования: } & \text { Принята к публикации: } \\ \text { 08.11.2021 } & 16.11 .2021 & 19.11 .2021\end{array}$

